\title{
Management switching angles real-time prediction by artificial neural network
}

\author{
Mohammed Rasheed Jubair Al-Hiealy, Mohammad Shahir Bin Abdul Majed Shikh, \\ Abdurrahman Bin Jalil, Suhaila Abdul Rahman, Muath Jarrah \\ Departmnet of Computer Engineering, University Malaysia of Computer Science \& Engineering (UNIMY), Selangor, \\ Malaysia
}

\section{Article Info}

Article history:

Received Nov 7, 2020

Revised Apr 27, 2021

Accepted May 10, 2021

\section{Keywords:}

Artificial intelligence

Harmonics optimization

Neural network ANN

Switching angle

\begin{abstract}
Artificial neural networks (ANNs) is an efficient way for different types of real-world prediction problems. In the past decade, it has given a tremendous surge in a global research activities. ANNs embody much certainty and provide a great deal of promise This paper has present artificial neural network (ANN) technique analysis and prediction for management switching angles real-time. The proposes to be used ANN for prediction and selected obtine angles for implement the timing diagram for mulitlvel inverter circuit. In order to control the fundamental component, ANNs are used to solve the analysis of non-linear equation of the output timing diagram in order to determine the switching angles. Substantially, the number of switching devices are reducing as possible basically for reducing a switching loss in the system, also have been used ANNs technique to optimize a switching angles behavior to reduce total harmonic distortion (THD) at voltage and current output waveform equal THDV $8.05 \%$ THDA $5.1 \%$. For the proposed controllers, the performance and results by the ANNs were obtained and compared by using MATLAB software.
\end{abstract}

This is an open access article under the CC BY-SA license.

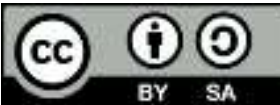

\section{Corresponding Author:}

Mohammed Rasheed Jubair Al-Hiealy

Department of Computer Engineering

University Malaysia of Computer Science \& Engineering (UNIMY)

Selangor, Malaysia

Email: rasheed.alhiealy@unimy.edu.my

\section{INTRODUCTION}

A multilevel inverter is an electronic circuit with multi-level power, this inverter/circuit can be converted into a direct power (DC) output supply and supplies an alternate voltage (AC) waveform. "Renewable sources of energy such as photovoltaics, wind and water turbines are now essential energy sources due to their renewable and environmental friendliness" [1]-[3]. Most of these renewable pathways generate a DC waveform as an output that is not appropriate for transmissions, distributions and uses. Based on this, the DC output power should be converted to AC power waveform and this can be achieved through the MLI circuit [2]-[5]. In general, based on their principal structure, MLI structures have been categorized into three main topologies namely cascaded h"bridge (CHB-MLI) which is the most common and reliable, diode-clamped (DC-MLI) and fly"capacitor (FC-MLI). A connected cells in series in the load compose a CHB-MLI topology, while conventional structure of CHB-MLI uses four switches producing three levels for each cell [4], [5]. Several modulation methods for eliminating a harmonic during the output waveform, such as the pulse wide module (PWM), called a high frequency switching technique, including S-PWM and SVPWM have been used. Secondly, selective harmonic elimination (SHE-PWM) method, often called the best 
modulation method, as the space vector control (SVC), is a fundamental technique for frequency changes [6][11]. "In addition, a complex transcendental not linear equation (SHE-PWM) can be found which has to be resolved, which cannot be easily solved by simple methods [12], while means of iterative control methods can overcome this complex equation (SHE-PWM) such as optimisation of artificial neural network (ANN), firesfly algorithm (FFA), particle swarm optimization (PSO), and newton-raphson (NR) [13]-[15] to define and calculate unique switching Angles for lower THD and more smooth wave form of a multiplex" [7], [12][15]. THD can essentially be defined as the ratio of high harmonics with low harmonics as shown, when an is a high harmonic and a1 low harmonics [16]. Therefore, output voltage can be generated by a nine level CHBMLI based on Figure 1 and Figure 2,

$$
\begin{aligned}
& \text { THD }=\frac{\sum_{n=1,3,5 \ldots}^{\infty}\left(a_{n}\right)}{a_{1}} \\
& V_{\text {out }}=V_{c 1}+V_{c 2}+V_{c 3}+V_{c 4}+V_{c 5}
\end{aligned}
$$

\section{SHE-PWM TECHNIQUE PROPOSED METHOD}

A selective harmonic elimination SHE-PWM technique from a fundamental switch frequency strategy is a modulation technique that has been used in this research paper. "To produce a symmetrical quarter waveform in this approach, the equation of the fast fourier series (FFT) is applied to the output voltage staircase waveform to satisfy the best switching angles [11]". The (Vout) FFT statement can be computed as,

$$
\mathrm{V}(\mathrm{t})_{\text {out }}=\sum_{\mathrm{n}=1}^{\infty} \mathrm{a}_{\mathrm{n}} \sin (\mathrm{n} \omega \mathrm{t})+\mathrm{b}_{\mathrm{n}} \cos (\mathrm{n} \omega \mathrm{t})
$$

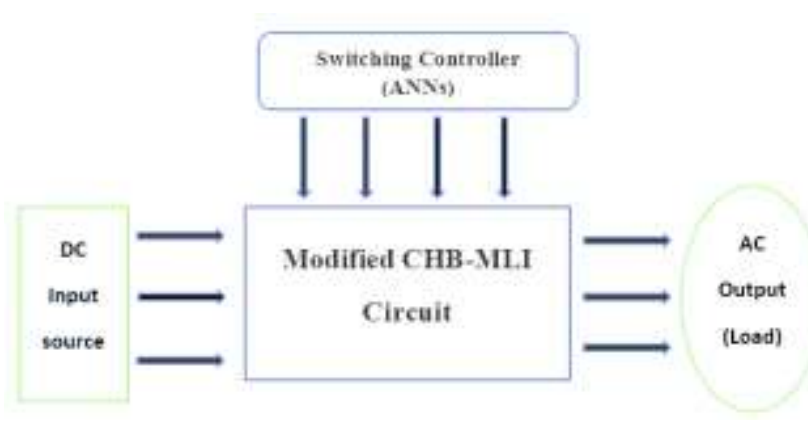

Figure 1. One of cell for nine level CHB-MLI

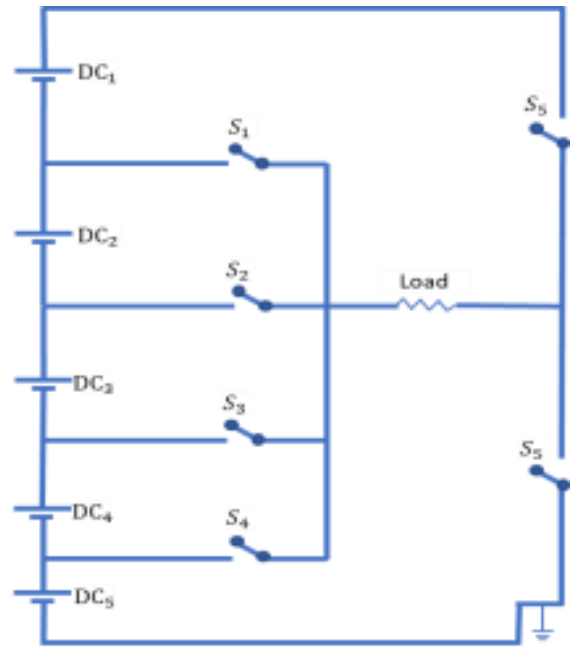

Figure 2. Proposal for nine-level CHB-MLI circuit

"Which cleared all kinds of harmonics (b nequal zero) and presented only the odd harmonics". "The odd coefficient (an) can therefore be determined, and the switching angles can only be calculated at the initial quadrant waveform." Thereby, 4 Switching Angles at level-9 MLI should be defined and calculated as the critical angle at first quadrant waveform $\left(\theta_{1}, \theta_{2}, \theta_{3}\right.$ and $\left.\theta_{4}\right)$ as shown in Figure 4 based on Table 1 [17]. The odd $\left(a_{n}\right)$ coefficient can, however, be calculated in,

$$
\mathrm{a}_{\mathrm{n}}=\frac{4}{\pi} \int_{0}^{\pi / 2} \mathrm{~V} \sin (\mathrm{n} \theta) \mathrm{d} \theta
$$

therefore the input supply units are required, assuming that the MLI which proposes the symmetrical CHBMLI is equivalent. The MLI output voltage waveform can then be defined by FFT expansion,

Management switching angles real-time prediction by artificial... (Mohammed Rasheed Jubair Al-Hiealy) 


$$
V(\omega t)=\frac{4 V_{d c}}{n \pi} \sum_{n=1,3,5, . .}^{\infty}\left[\cos \left(n \theta_{1}\right)+\cos \left(n \theta_{2}\right)+\cos \left(n \theta_{3}\right)+\cos \left(n \theta_{4}\right)\right] \frac{\sin (n \omega t)}{n}
$$

in fact, the odd coefficient ( $\left.a_{n}\right)$ of fourier series (FFT), "which can be obtained by taking $V(\omega t)$ as the common factor for every equation side, needs to be further analysed" [18]. until the final equation of odd series coefficients for harmonic order components can be obtained in,

$$
a_{n}=\frac{4 V_{d c}}{n \pi}\left[\cos \left(n \theta_{1}\right)+\cos \left(n \theta_{2}\right)+\cos \left(n \theta_{3}\right)+\cos \left(n \theta_{4}\right)\right]
$$

numerically, 4 orders can be obtained for each strange harmonic order at 9-level CHB-MLI in (Figure 3),

$$
\begin{aligned}
& {\left[\cos \left(\theta_{1}\right)+\cos \left(\theta_{2}\right)+\cos \left(\theta_{3}\right)+\cos \left(\theta_{4}\right)\right]=\frac{4 \pi \mathrm{M}_{\mathrm{i}}}{2}} \\
& {\left[\cos \left(3 \theta_{1}\right)+\cos \left(3 \theta_{2}\right)+\cos \left(3 \theta_{3}\right)+\cos \left(3 \theta_{4}\right)\right]=0} \\
& {\left[\cos \left(5 \theta_{1}\right)+\cos \left(5 \theta_{2}\right)+\cos \left(5 \theta_{3}\right)+\cos \left(5 \theta_{4}\right)\right]=0} \\
& {\left[\cos \left(7 \theta_{1}\right)+\cos \left(7 \theta_{2}\right)+\cos \left(7 \theta_{3}\right)+\cos \left(7 \theta_{4}\right)\right]=0}
\end{aligned}
$$

and modulation index $\mathrm{M}_{\mathrm{i}}=\frac{\mathrm{a}_{1}}{\mathrm{lV}_{\mathrm{dc}}}$ when $\mathrm{l}$ "the number of independent DC sources., in fact, a mathematical equation cannot determine the complex SHE-PWM equation. Complicated approaches ANN, FFA, PSO, and N-R must virtually be calculated" [19], [20].

Table 1. Output voltage switching behavior for nine-leve M-CHB-MLIs

\begin{tabular}{ccccccc}
\hline $\mathrm{S}_{1}$ & $\mathrm{~S}_{2}$ & $\mathrm{~S}_{3}$ & $\mathrm{~S}_{4}$ & $\mathrm{~S}_{5}$ & $\mathrm{~S}_{6}$ & $\mathrm{~V}_{\mathrm{o}}$ \\
\hline 1 & 0 & 0 & 1 & 0 & 1 & $\mathrm{Vdc}_{\mathrm{dc}} / 2$ \\
1 & 0 & 0 & 1 & 0 & 0 & $\mathrm{~V}_{\mathrm{dc}} / 3$ \\
0 & 0 & 0 & 1 & 1 & 0 & $\mathrm{~V}_{\mathrm{dc}} / 4$ \\
0 & 0 & 0 & 1 & 1 & 0 & 0 \\
0 & 0 & 1 & 1 & 0 & 0 & $0^{*}$ \\
1 & 1 & 0 & 0 & 0 & 1 & $-\mathrm{V}_{\mathrm{dc}} / 4$ \\
0 & 1 & 0 & 0 & 1 & 1 & $-\mathrm{V}_{\mathrm{dc}} / 3$ \\
0 & 1 & 0 & 0 & 1 & 0 & $-\mathrm{V}_{\mathrm{dc}} / 2$ \\
0 & 1 & 1 & 0 & 0 & 0 & \\
0 & 1 & 1 & 0 & 0 & 0 & $-\mathrm{Vdc}^{2}$
\end{tabular}

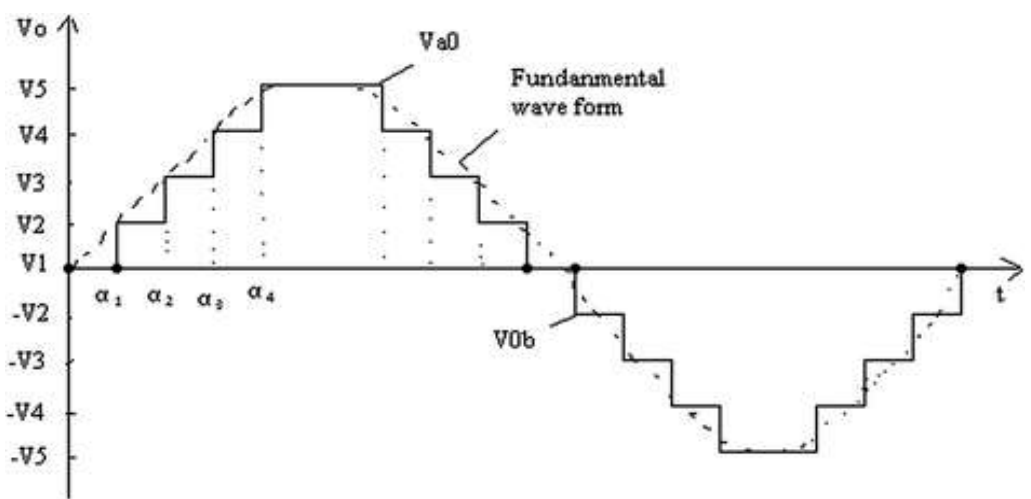

Figure 3. Output waveform voltage of 9-level MLI

\section{ANN PERFORMANCE EVALUATION}

ANNs are inspired by biological nervous system, it can organise and process information and evaluate the desired data as shown in Figure 4 [15], it is a powerful technique that has been successfully applied and solved various types of real-world problems, particularly in the field of electronic control. A fundamental structure model for ANNs are compiled by the number of layers that have a limited number of 
activation functions that called neurons; they are interconnected by connecting weight so that each layer has a bias parameter, in which a regulatory value is used, to control a processing method [16] ANNs generally have three major layers of weight connection: input layer to hold the input parameters, hidden layers as a processing layer and finally the output layer of the result from input and processing layers [17]-[19].

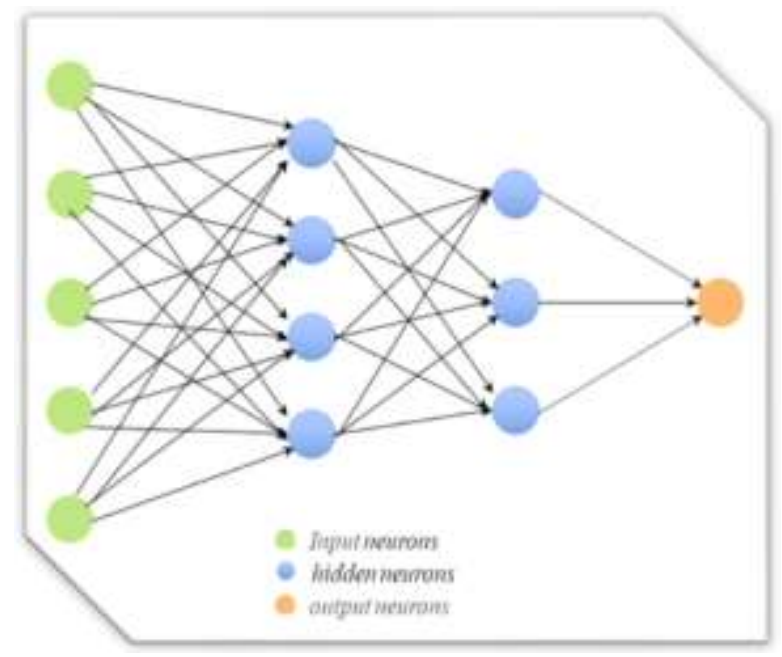

Figure 4. ANNs structure

Feedback (FB-ANNs) which contain feedback and feedback unit (FF-ANNs) and which do not contain the feedback unit, may also be divided into two main structures. In fact, it has been established that all ANNs need first of all to train data to understand and to form a link between the output and input layers in order to respond more quickly and temporarily [21]. There is different training algorithms used in ANNs. However, the most appropriate algorithm in this work is Levenberg-Marquardt-algorithm, which is required to reduce the memory compared to other methods because of faster tanning [22]. Results with high performance compared to other studies that used different control methods were achieved by using ANNs as a control system to calculate nonlinear transcendental equation because the ability to map the fundamental relationship between input and output data during the training process was achieved [23]. As an input neuron, the first neuron of the output layer is used to generate a switching signal for the proposed M-CHBMI [24]. For $i^{\text {th }}$ neuron at $m^{\text {th }}$ ayer the network transfer function can then be described in,

$$
n_{i}^{m}=\sum_{j=1}^{S^{m-1}} W_{i j}^{m} a_{j}^{m-1}+b_{i}^{m}
$$

the parameter of bias of $j^{\text {th }}$ layer at $i^{\text {th }}$ neuron is the $W_{i j}^{m}$ weight relations parameter for the $m^{\text {th }}$ and $i^{\text {th }}$ neurons at the $m^{t h}$ layer and the $b_{i}^{m} . a_{j}^{m}$ is also the at $m^{t h}$ layer neuron output function that can be defined as:

$$
\mathrm{a}_{\mathrm{i}}^{\mathrm{m}}=\mathrm{f}^{\mathrm{m}}\left(\mathrm{n}_{\mathrm{i}}^{\mathrm{m}}\right)
$$

In the hidden layer, a tangent hyperbolic function is selected as the activation function $(f)$ for our network design, it can be defined as,

$$
\mathrm{f}^{\mathrm{m}}\left(\mathrm{n}_{\mathrm{i}}^{\mathrm{m}}\right)=\frac{2}{1+\mathrm{e}^{-2 \mathrm{n}_{\mathrm{i}}^{\mathrm{m}}}}-1
$$

whereas $f$ is unity at the output layer [25]-[27]. The above describes a harmonic minimization equation using ANNs. Figure 5 shows the ANN harmonic minimization procedure flow chart and Figure 6 provides the resulting optimal switching angles. ANNs consisting of two hidden neurons have been training the output are shown in Figure 7(a) and Figure 7(b) showing the gradient mean squared error and ANN performance validation of 9-level modified CHB-MLI that has also been used to update and correct both network device weight and bias values, validation is used via the training process to track the error. 


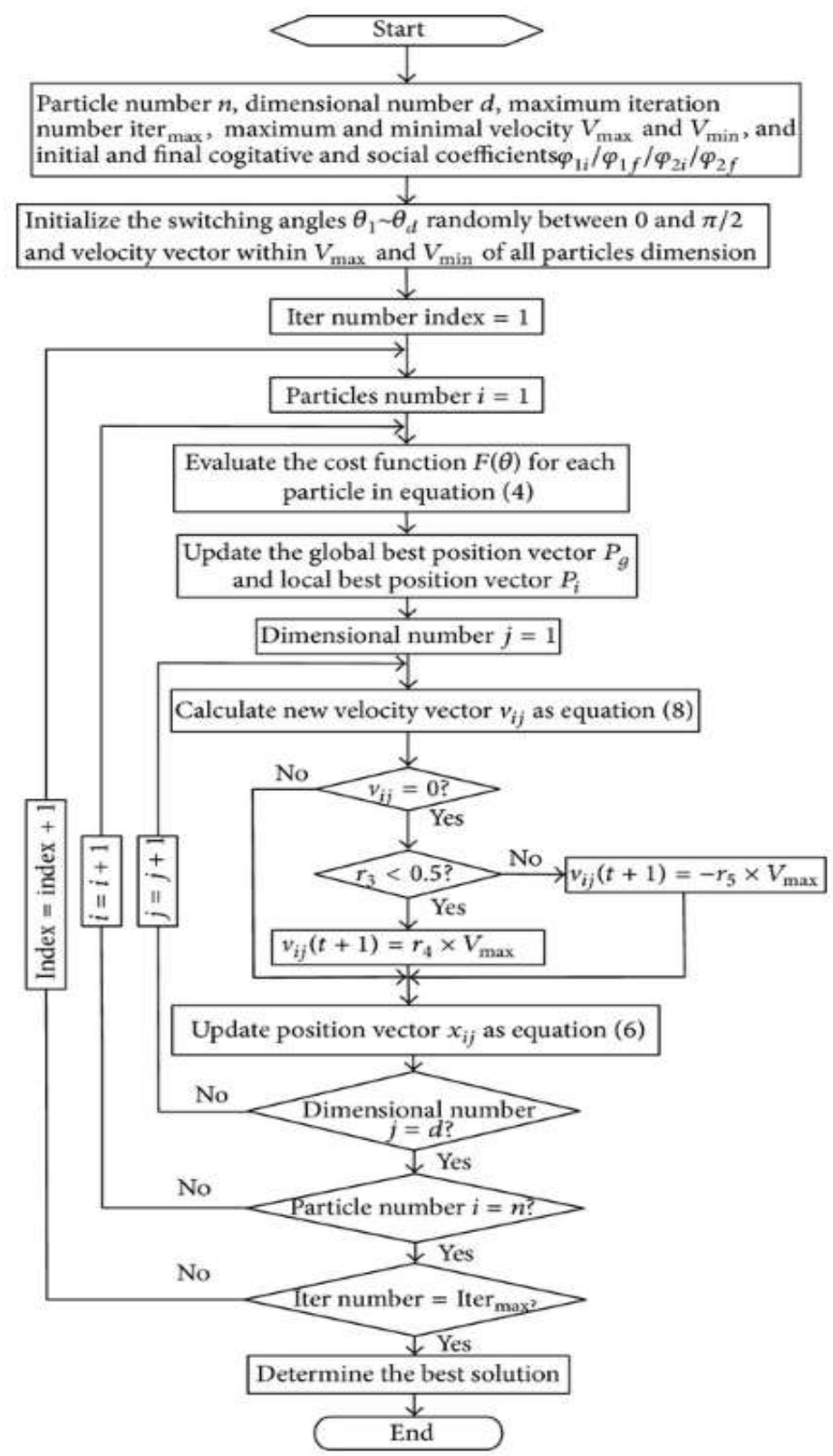

Figure 5. ANN flow chart for harmonics problem of minimization

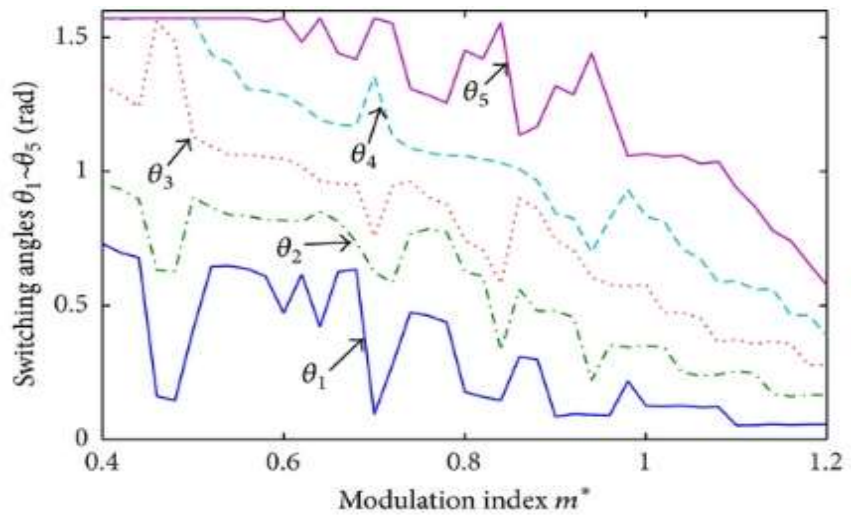

Figure 6. Calculated switching angles $\theta_{1}, \theta_{2}, \theta_{3}$, and $\theta_{4}$ 


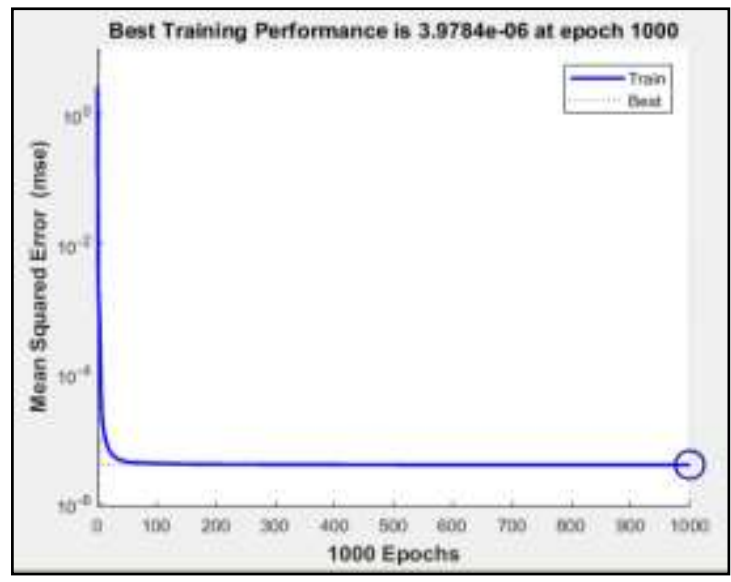

(a)

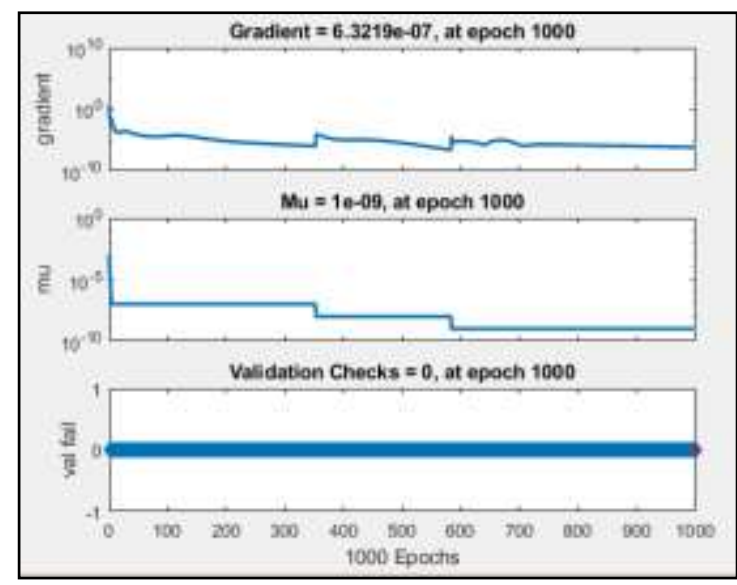

(b)

Figure 7. ANN Performance at training with 2 neurons in hiding

\section{NINE LEVEL CHB-MLI MATLAB SIMULABION OF MODIFIED}

The proposed system consists of one modificated cell connected to a series each containing pulse generating unit, as a switching control system, as shown in Figure 8, using MATLAB simulation software.

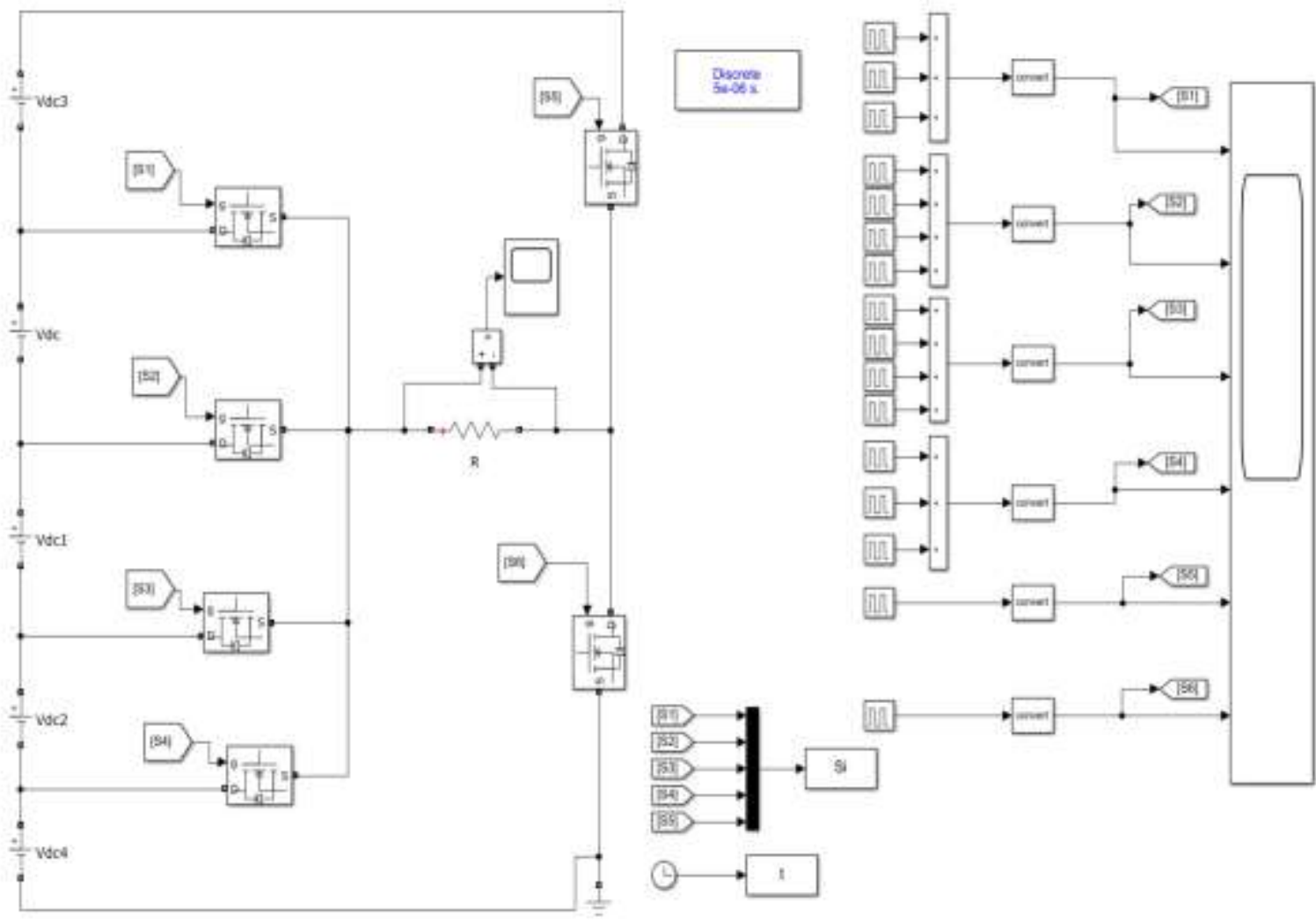

Figure 8. Matlab 9-level CHB-MLI simulation

\section{SIMULATION OPTIMIZATION RESULTS FOR SINGLE-PHASE MODIFIED CHB-MLIS NINE- LEVEL WITH MI= 0.9 BASED ON ANN TECHNIQUES}

In order to produce 4 initial switching angles that are used to control a 9-level modified CHB-MLI, an artificial neural network (ANN) of a single-phase waveform system has been developed using MATLAB/software code. Five separate DC input sources, each equal to $300 \mathrm{~V}$ and $2500 \mathrm{~Hz}$ switching 
frequency, were also assumed. This system generates AC waveforms on the load side to feed a single-phase load of R $80 \Omega, \mathrm{H} 35 \mathrm{e}-3 \mathrm{~L}$ and $\mathrm{C} 50 \mathrm{e}-6 \mathrm{mF}$. The initial 4 switching angles using an ANN approach for the time frame of $\mathrm{Mi}=0.9$ have resulted $\theta 1=7.871, \theta 2=20.054, \theta 3=44.125, \theta 4=52.831 \theta 5=52.831$ and $\theta 6=52.831$, even the time frame for each loop for each output waveform is equal to 0.02 . The prediction data and original data for total harmonic distortion (THD) are listed in Figure 9 during test time. Training performance of ANN testing angles set are illustrated in Figure 10 that indicating error resultant are $\mathrm{R}=80$. A 9-level CHB-MLI at have been developed by simulation mode in which include one modified cell each cell at the system contains two units (switching circuit scheme unit and control unit) each cell consisting 4 switching devices in structure scheme with one pulse generator at control unit for each one of them. Figure 11 shows the timing of control pules with real switching times of each switch on the device using ANN optimization angles of switching during a three-cell cell model one $S_{1}, S_{2}, S_{3}$ and $S_{4}$. The resultant total harmonic distortion (THD) that have been provide using ANN switching angles optimization technique to control a single-phase modified 9-level CHB-MLI are reduced as compared with other optimization techniques like NR and PSO at both of current and voltage parameters in which a voltage THD have been reached into 5\% and current THD have been reached into $1.3 \%$ as shown in Figure 12-15.

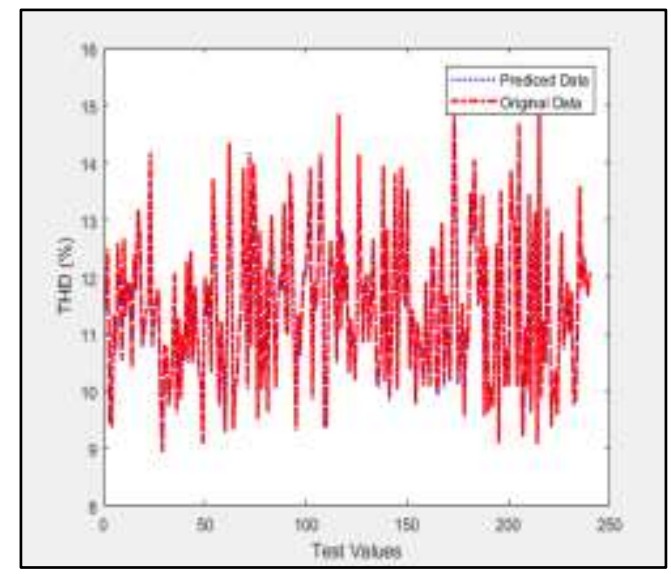

Figure 9. Predicted data and original data for THD

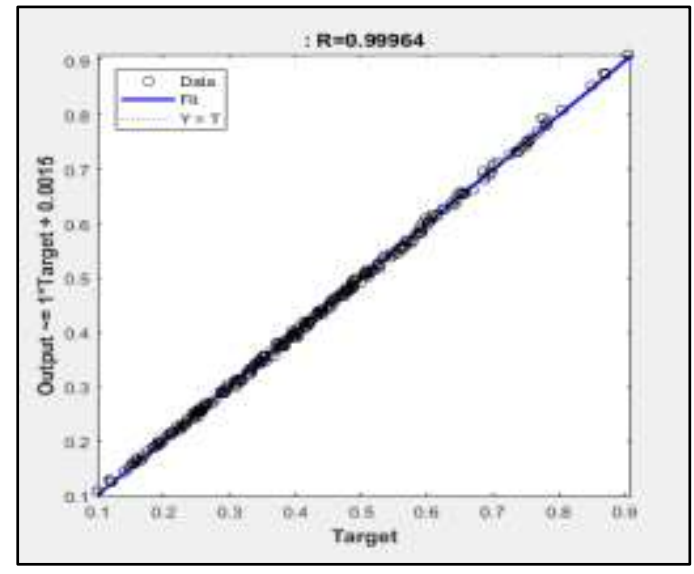

Figure 10. Training performance angles for ANN
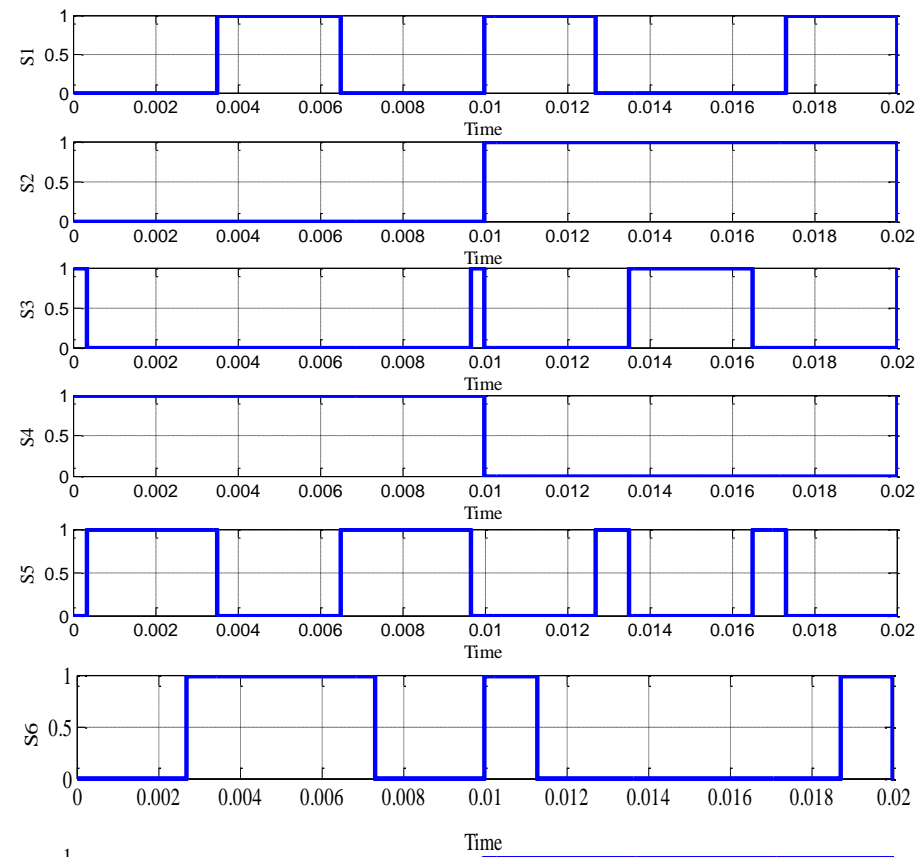

Figure 11. Time switching for $S_{1}, S_{2}, S_{3}, S_{4}, S_{5}$ and $S_{6}$ 
The proposed 5 and 9-level single-phase modified CHB-MLI was previously used by the ANN technique for the purpose of reducing the THD on the voltage and current output waveform as shown in Figure 16. "For five-level and nine-level modified CHB-MLI", Table 2 "displays switching angles and different THDs in voltage and current".

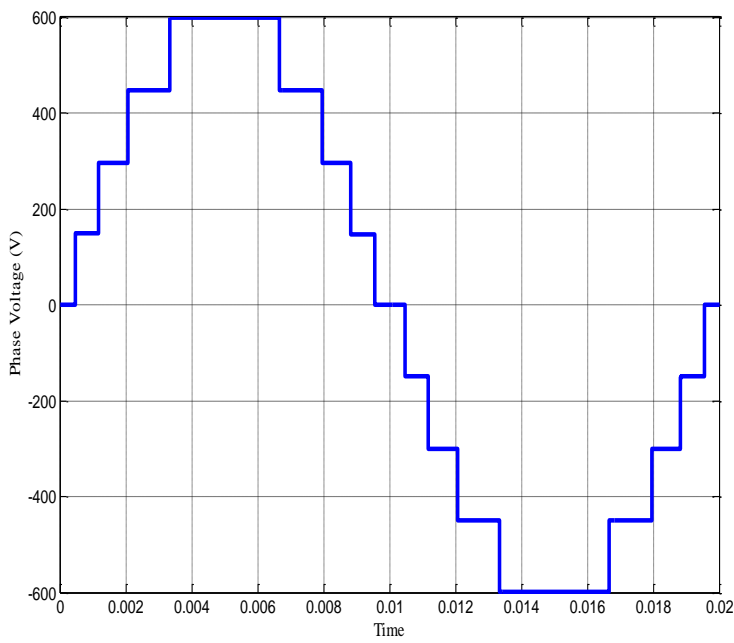

Figure 12. Output voltage waveform for 9-level CHB-MLI simulation

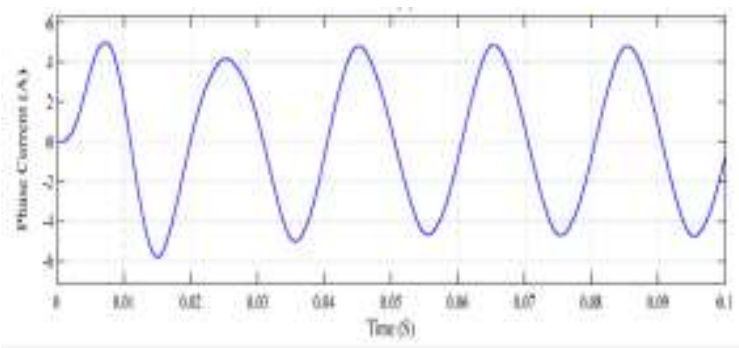

Figure 14. Output current waveform for 9-level CHB-MLI simulation

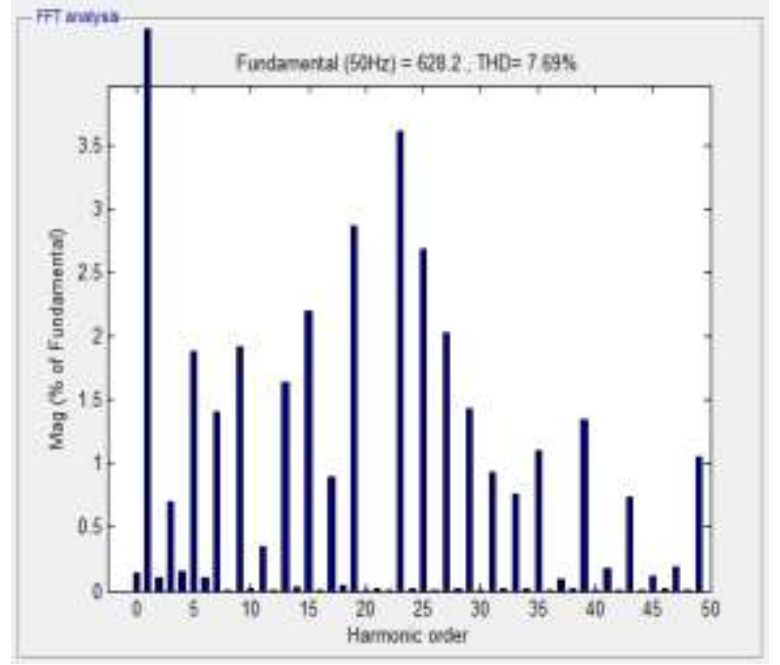

Figure 13. Output harmonic spectrum for voltage waveform using ANN technique

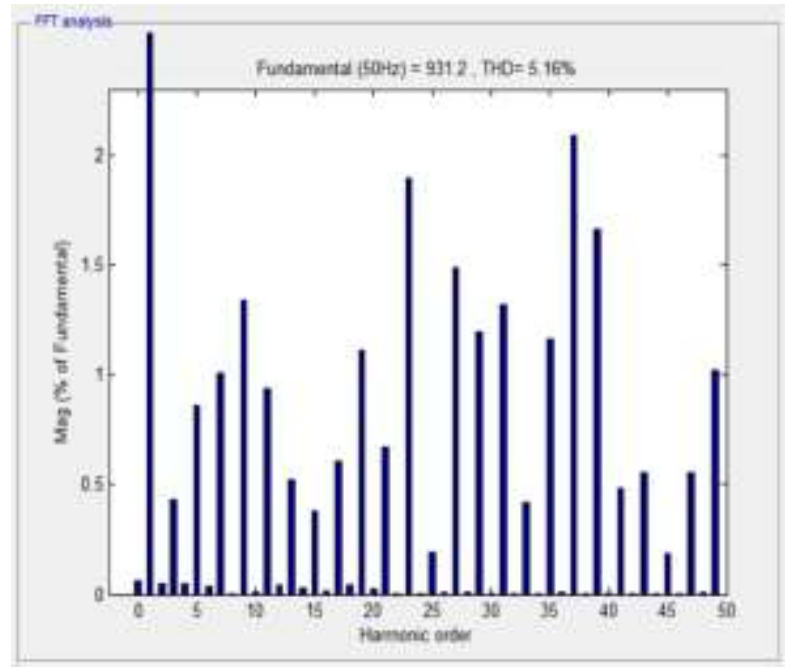

Figure 15. Output harmonic spectrum for current waveform using ANN technique

Table 2. Comparison of the 5 and 9 levels of the modified CHB-MLI based on the ANN proposal

\begin{tabular}{cccccccc}
\hline N-level & MI & $\theta_{1}$ & $\theta_{2}$ & $\theta_{3}$ & $\theta_{4}$ & $\mathrm{THD}_{\mathrm{V}}$ & $\mathrm{THD}_{\mathrm{A}}$ \\
\hline 5-level & 0.9 & 31.41 & 41.93 & 0 & 0 & $14.48 \%$ & $8.05 \%$ \\
9-level & 0.9 & 7.871 & 20.05 & 44.12 & 52.83 & $7.46 \%$ & $5.1 \%$ \\
\hline
\end{tabular}




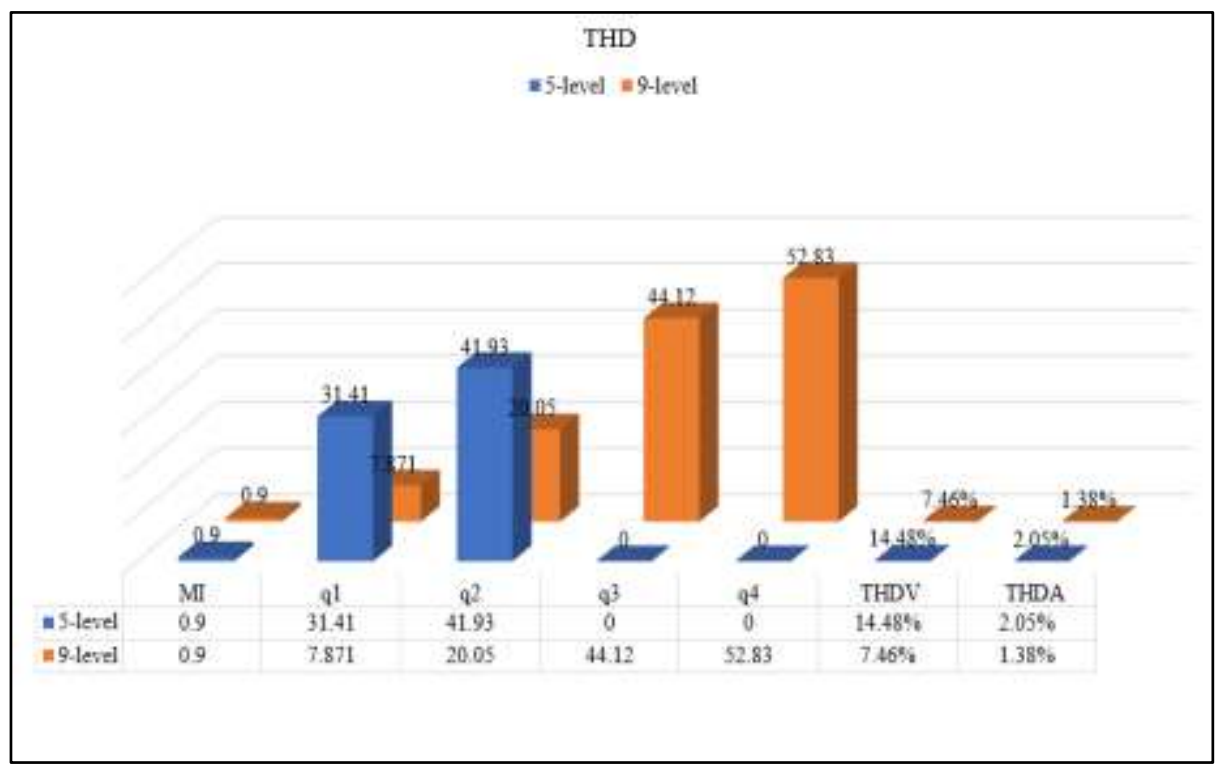

Figure 16. Statistics graph for switching angle values and the THD values of voltage and current based on ANN for 9-levels M-CHB-MLI

\section{CONCLUSIONS}

The research paper proposes ANNs as the nine-level CHB-MLI optimization method that reduces THD 's current waveform and output voltage. The aim of this paper was simulated with MATLAB Simulink to analyse the resulting parameters. The resultant THD output wave form of 9-level has been compared with a resultant THD output waveform of previous work of research papers for 5-level CHB-MLI. In briefly describe of simulation result, the THD at output waveform are reduced when the level stepped of CHB-MLI are increased, also ANNs technique a useful optimization tool that provide lower THD as compared with NR and PSO optimization techniques.

\section{REFERENCES}

[1] M. Rasheed, M. M. A. Alakkad, R. Omar, M. Sulaiman, and W. A. Halim, "Enhance the accuracy of control algorithm for multilevel inverter based on artificial neural network," Indones. J. Electr. Eng. Comput. Sci. (IJEECS), vol. 20, no. 3, 2020, doi: 10.11591/ijeecs.v20.i3.pp1148-1158.

[2] R. Omar, M. Rasheed, M. Sulaiman, and A. Al-janad, "A Study of a Three Phase Diode Clamped Multilevel Inverter Performance For Harmonics Reduction,” MAGNT Res. Rep. (ISSN. 1444-8939), vol. 2, no. 4, pp. 62-71.

[3] P. Chowdhury, I. Koley, and S. Sen, "Modelling, simulation and control of a grid connected non conventional solar power generation system using,” vol. 2, no. 4, pp. 1183-1191, 2013

[4] K. Goswami, B. Pandey, D. M. A. Hussaian, T. Kumar, and K. Kalia, "Input / output Buffer based Vedic Multiplier Design for Thermal Aware Energy Efficient Digital Signal Processing on 28nm FPGA," Indian Journal of Science and Technology, vol. 9, no. March 2016, pp. 1-8, doi: 10.17485/ijst/2016/v9i10/88072.

[5] G. Vijaykrishna and O. C. Shekhar, "A Three Phase 7-Level and 9-Level Reversing Voltage Multilevel Inverter," Indian Journal of Science and Technology, vol. 8, no. September 2015, pp. 1-10, doi: 10.17485/ijst/2015/v8i.

[6] M. M. A. Alakkad, Z. Rasin, M. Rasheed, W. A. Halim, and R. Omar, "Real-time switching thirteen-level modified CHB-multilevel inverter using artificial neural network technique based on selective harmonic elimination," Indones. J. Electr. Eng. Comput. Sci. (IJEECS), vol. 20, no. 3, 2020, doi: 10.11591/ijeecs.v20.i3.pp1642-1652.

[7] R. Omar, M. Rasheed, Z. K. Low, and M. Sulaiman, "Design and development of active power filter for harmonic minimization using synchronous reference frame (SRF)," ARPN J. Eng. Appl. Sci., vol. 14, no. 2, 2019.

[8] J. S. Krismadinataa, Nasrudin Abd. Rahima Hew Wooi Pinga, "The 3 rd International Conference on Sustainable Future for Human Security Photovoltaic module modeling using simulink/matlab," Procedia Environ. Sci., vol. 17, no. 3, 2013, pp. 537-546, doi: 10.1016/j.proenv.2013.02.069.

[9] N. Nordin, Syuhada, R. Omar, M. Rasheed, A. Sabari, and K. Krismadinata, "Harmonic minimization of a three phase cascaded hbridge multilevel inverters," in IET Conference Publications, 2016, no. CP688, 2016.

[10] H. F. Hashim, R. Omar, and M. Rasheed, "Design and analysis of a three phase series active power filter (sapf) based on hysteresis controller," in IET Conference Publications, 2016, no. CP688, 2016.

[11] M. Rasheed, R. Omar, and M. Sulaiman, "Comparative performance of multilevel inverter for harmonic reduction based on Newton raphson," in IET Conference Publications, 2016, no. CP688, 2016. 
[12] J. Rodríguez, Steffen Bernet, Bin Wu, Jorge O. Pontt, and Samir Kouro, "Multilevel Voltage-Source-Converter Topologies for Industrial Medium-Voltage Drives," IEEE Trans. Ind. Electron., vol. 54, no. 6, pp. 2930-2945, 2007, doi: 10.1109/TIE.2007.907044.

[13] S. S. Patnaik and A. K. Panda, "Three-level H-bridge and three H-bridges-based three-phase four-wire shunt active power filter topologies for high voltage applications," Int. J. Electr. Power Energy Syst., vol. 51, pp. 298-306, Oct. 2013, doi: 10.1016/j.ijepes.2013.02.037.

[14] L. M. Tolbert, S. Member, and F. Z. Peng, "Multilevel PWM Methods at Low Modulation Indices," IEEE Trans. POWER Electron., vol. 15, no. 4, pp. 719-725, 2000, doi: 10.1109/63.849042.

[15] H. H. Wang, S. Member, A. M. Khambadkone, and S. Member, "Analytical Power Loss Evaluation of 5 level HBridge with Coupled Inductor and Series Connected H-Bridge for PEBB Applications," Power Electron. Drive Syst. 2009. PEDS 2009, vol. 1, pp. 458-463, 2009, doi: 10.1109/PEDS.2009.5385922.

[16] M. S. Rosli Omar, Mohammed Rasheed, "Fundamental Studies of a Three Phase Cascaded H-Bridge and Diode Clamped Multilevel Inverters Using Matlab/Simulink," Int. Rev. Autom. Control, vol. 6, no. 5, 2013.

[17] A. Parkash and S. L. S. Chatterji, "Harmonics Elimination in Cascade Multilevel Inverters Using Newton-Raphson and Genetic Algorithm," Int. J. Sci. Res. Dev., vol. 2, no. 5, pp. 236-239, 2014.

[18] M. Sabahi, A. R. M. Iranaq, K. M. Bahrami, K. M. Bahrami, and M. B. B. Sharifian, "Harmonics elimination in a multilevel inverter with unequal DC sources using genetic algorithm," 2011 Int. Conf. Electr. Mach. Syst. ICEMS 2011, 2011, doi: 10.1109/ICEMS.2011.6073451.

[19] A. Parkash, S. L. Shimi, and S. Chatterji, "Harmonics Reduction in Cascade H-Bridge Multilevel Inverters Using GA and PSO," vol. 12, no. 9, pp. 453-465, 2014, doi:10.14445/22315381/IJETT-V12P287.

[20] C. Y. H'ng, B. Ismail, M. Isa, and M. N. K. H. Rohani, "Selective harmonic elimination pulse width modulation for five-level cascaded inverter," J. Telecommun. Electron. Comput. Eng., vol. 10, no. 1-14, pp. 67-71, 2018.

[21] P. G., "Optimization Techniques for Harmonics Minimization in Cascaded Hybrid Multilevel Converters: a Review," Int. J. Res. Eng. Technol., vol. 04, no. 03, pp. 188-193, 2015, doi: 10.15623/ijret.2015.0403033.

[22] R. Taleb and A. Meroufel, "Control of asymmetrical multilevel inverter using artificial neural network," Elektron. ir Elektrotechnika, no. 8, pp. 93-98, 2009, doi: 10.5755/j01.eee.96.8.9970.

[23] R. Taleb, A. Meroufel, and P. Wira, "Harmonic elimination control of an inverter based on an artificial neural network strategy," IFAC Proc., vol. 2, no. part 1, pp. 137-156, 2009, doi: 10.3182/20090921-3-TR-3005.00007.

[24] M. Mahesh, K Kranthi, and P. Singh, "Artificial Neural Network Based Closed Loop Control of Multilevel Inverter," Int. J. Mod. Trends Sci. Technol., no. 2, 2016.

[25] W. A. H. and M. M. A. Mohammad Rasheed, Rosli Omar, Marizan Sulaiman, "Artificial Intelligence Technique to Real-Time Based on Selective Harmonic Elimination in Modified Multilevel Inverter," J. Eng. Appl. Sci., vol. 14, no. 24 , p. 9, 2019.

[26] H. A. Mohamed and H. M. D. Habbi, "Power quality of dual two-level inverter fed open end winding induction motor," Indones. J. Electr. Eng. Comput. Sci. (IJEECS), vol. 18, no. 2, pp. 688-697, 2020, doi: 10.11591/ijeecs.v18.i2.pp688-697.

[27] M. Rasheed, R. Omar, M. Sulaiman, W. A. Halim, and M. M. A. Alakkad, "Analysis of a switching angle calculation by ANN for nine level inverter apply into experimental case study with elimination of lower and higher order harmonics," Indones. J. Electr. Eng. Comput. Sci. (IJEECS), vol. 20, no. 2, pp. 948-959, 2020, doi: 10.11591/ijeecs.v20.i2.pp948-959.

[28] Mohamad Jaya, A. S, Jarrah, M, and Muhamad, M. R, "Modeling of TiN coating grain size using RSM approach," In Applied Mechanics and Materials, vol. 754, pp. 738-742, Trans Tech Publications Ltd, 2015, doi: 10.4028/www.scientific.net/AMM.754-755.738.

[29] Jarrah, M. I, Jaya, A. S. M, Alqattan, Z. N, Azam, M. A, Abdullah, R, Jarrah, H, and Abu-Khadrah, A. I, "A novel explanatory hybrid artificial bee colony algorithm for numerical function optimization.," The Journal of Supercomputing, pp.1-25, 2020, doi: 10.1007/s11227-019-03083-2.

[30] Jarrah, M. I. M, Jaya, A. S. M, Azam, M. A, Alqattan, Z. N, Muhamad, M. R, and Abdullah, R, "Application of Bat Algorithm in Carbon Nanotubes Growing Process Parameters Optimization," In Intelligent and Interactive Computing, pp. 179-192, Springer, Singapore, 2019, doi: 10.1007/978-981-13-6031-2_14.

[31] Jarrah, M. A. I, Jaya, A. S. M, Azam, M. A, Alsharif, M. H, and Muhamad, M. R, "Intelligence Integration Of Particle Swarm Optimization And Physical Vapour Deposition For Tin Grain Size Coating Process Parameters," Journal of Theoretical \& Applied Information Technology, vol. 84, no. 3, 2016.

[32] Jarrah, M. I, Jaya, A. S. M, Azam, M. A, Muhamad, M. R, and Zain, A. M, "Prediction of Grain Size in the TiN Coating Using Artificial Neural Network,"International Journal of Applied Engineering Research, vol. 11, no. 19, pp. 9856-9869, 2016.

[33] Fauzi, N. F, Abdul Syukor Mohamad Jaya, M. I. Jarrah, Hussain Salih Akbar, "Thin film roughness optimization in the TiN coatings using genetic algorithms," J Theor Appl Inf Technol, vol. 95, no. 24, pp. 6690-6698, 2017. 